\title{
Arabinogalactan proteins: actors or spectators during abiotic and biotic stress in plants?
}

This is the peer reviewed version of the following article:

Original:

Mareri, L., Romi, M., Cai, G. (2019). Arabinogalactan proteins: actors or spectators during abiotic and biotic stress in plants?. PLANT BIOSYSTEMS, 153(1), 173-185 [10.1080/11263504.2018.1473525].

Availability:

This version is availablehttp://hdl.handle.net/11365/1053228

since 2018-11-23T13:26:20Z

Published:

DOI:10.1080/11263504.2018.1473525

Terms of use:

Open Access

The terms and conditions for the reuse of this version of the manuscript are specified in the publishing policy. Works made available under a Creative Commons license can be used according to the terms and conditions of said license.

For all terms of use and more information see the publisher's website.

(Article begins on next page) 


\title{
Arabinogalactan proteins: actors or spectators during abiotic and biotic stress in plants?
}

\author{
Lavinia Mareri, Marco Romi and Giampiero Cai

\begin{abstract}
Arabinogalactan proteins (AGPs) are a family of hydroxyproline-rich glycoproteins (HRGP) ubiquitous in the plant kingdom. They are probably one of the most heterogeneous and complex families of macromolecules, making them able to perform different and multiple functions. Located at the plasma membrane-cell wall interface, AGPs are involved in several processes, from plant growth and development to reproduction. An additional function of AGPs in response to biotic and abiotic stress has been suggested by several studies. The purpose of this review is to summarize critically and analytically the available knowledge on the effects of abiotic stress (low and high temperatures, drought, flooding, anoxia and metal deficiency/toxicity) and biotic stress (bacteria, fungi, nematodes and viruses) on AGPs. A deeper understanding of the role of AGPs during these conditions can be an important tool for understanding AGP biology and for the possible development of efficient breeding strategies.
\end{abstract}

\section{ARTICLE HISTORY}

Received 2 May 2018

Accepted 3 May 2018

\section{KEYWORDS}

Arabinogalactan proteins; biotic stresses; abiotic stresses; plant development; plant reproduction

\section{Introduction}

Plants are sessile organisms and, because of their immobility, they are not able to escape all the stresses that occur in the environment. The two main stress categories that threaten plant survival are categorized in abiotic and biotic stress. Abiotic stress includes all stresses caused by non-living factors such as low and high temperatures, drought, high salinity, excessive light, flooding, hypoxia/anoxia and metal deficiency/toxicity; biotic stress is caused by living organisms such as bacteria, fungi, nematodes and viruses that can infect and damage plant tissues.

Plant organisms have evolved different strategies to avoid and/ or tolerate stresses. Strategies involve multiple signal transduction pathways in which different classes of molecules act synergistically and antagonistically. Among these molecules, it is likely to include arabinogalactan proteins (AGPs). AGPs are a subfamily of hydroxyproline-rich glycoproteins (HRGPs) ubiquitous in plant kingdom, probably occurring in every plant cell from bryophytes to angiosperms (Showalter 2001; Ellis et al. 2010). Schematically, AGPs are composed of a polypeptide (protein backbone) and a large and highly branched glycan chain rich in arabinose and galactose (Ellis et al. 2010; Showalter and Basu 2016). In most conditions, glycosylphosphatidylinositol (GPI) anchor signals characterize the C-terminal of AGPs (Borner et al. 2003). AGPs show a high degree of glycosylation with the carbohydrate component representing more than the $90 \%$ of the macromolecule (Seifert and Roberts 2007; Ellis et al. 2010; Hijazi et al. 2014; Nguema-Ona et al. 2014). The variable combination and arrangements of different monosaccharides are responsible for the great heterogeneity of AGPs. On the basis of the structure of the protein core, AGPs are divided into two main groups: "classical" and "non-classical" AGPs (Mau et al. 1995; Du et al. 1996; Showalter 2001). "Classical" AGPs are characterized by three parts: an $\mathrm{N}$-terminal signal peptide, a central domain of variable length containing Pro, Ala, Ser and Thr (PAST) as the major amino acid constituents, and a C-terminal GPI anchor signal that lacks in the non-classical AGPs (Youl et al. 1998; Schultz et al. 2000). The other type of classical AGPs are named AG peptides because of the nature of protein backbone only composed of 10-15 amino acids in length. In addition to "classical" and "non-classical" AGPs, there are also chimeric AGPs characterized by different conservative domains. These chimeric forms of AGPs are classified into three main subfamilies: fasciclin-like AGPs (FLA; Johnson et al. 2003; Ma and Zhao 2010; MacMillan et al. 2015), phytocyanin-like AGPs (PAG; Ma et al. 2011; Mashiguchi et al. 2009) and xylogen-like AGPs (Kobayashi et al. 2011). Moreover, molecules with characteristics of both AGPs and extensins (EXT) are known as AGP-extensins hybrids (HAE) (Showalter et al. 2010). FLAs protein families contain an ancient domain called fasciclin (FAS) which is conserved across bacteria, fungi, algae, insects and animals. FAS domains are proposed to be involved in cell adhesion, but the mechanism is not well understood. A total of 21 members were predicted in Arabidopsis (Johnson et al. 2003), 27 in rice (Ma and Zhao 2010) and 19 in cotton (Huang et al. 2008). In Arabidopsis, despite the limited similarity in the deduced proteins, the analysis of sequence highlighted two highly conserved regions that define FLA motif, indicating that the cell adhesion function is maintained (Johnson et al. 2003). Phytocyanin-like AGPs are phytocyanin (PCs) like molecules with arabinogalactan 


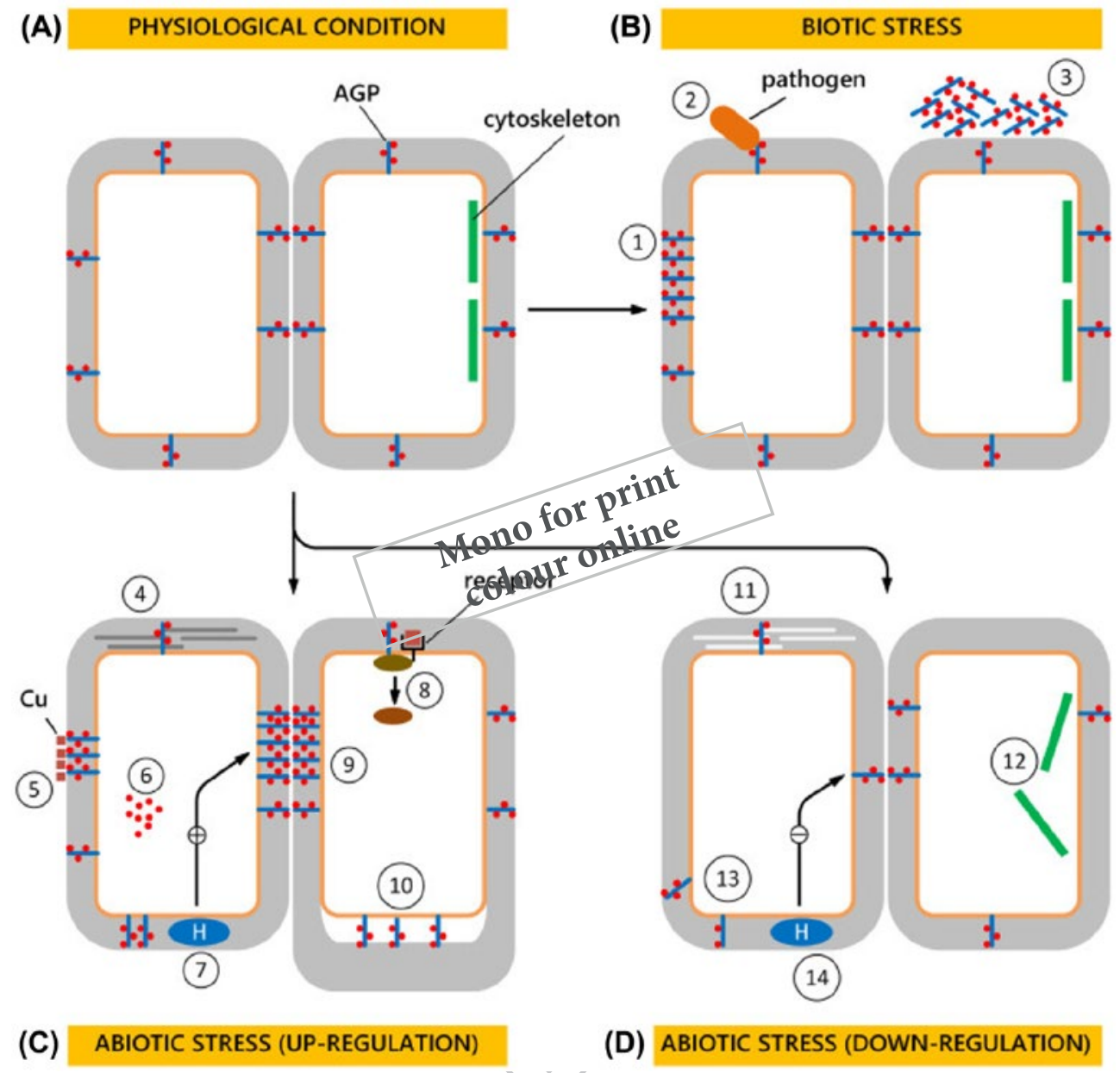

Figure 1. Schematic representation of the effects of abiotic/biotic stresses on AGPs biology. The picture represents plant cells with only a few basic elements such as AGP, the plasma membrane, the cell wall, the receptor system and the cytoskeleton. Under physiological condition AGPs are located on the plasma membrane-cell wall interface where they participate in many biological processes (A). Under biotic stress the expression of AGPs can be involved in many functions (B): (1) creation of an impermeable barrier by their reciprocal cross-linking. (2) recognition and attachment of plant pathogen; (3) synthesis of a "biofilm" that represents a mechanical barrier that limits pathogen infection (antimicrobial properties of the biofilm have also been reported). Under abiotic stress conditions AGPs can be up-regulated (C) or downregulated (D). The main consequences of their up-regulation are: (4) thickening and/or rigidification of cell wall by oxidative crosslinking; (5) create a buffer effect capturing ions in excess (e.g. Cu); (6) release of free sugars that protect plant cell from stressing conditions; (7) increase in their content by hormone (H) stimuli; (8) mediate the stress signalling response by the formation of complexes that facilitate the interaction between molecules of the signalling pathways; (9) enhance cell-cell communication; (10) forming a "buffer zone" that prevents the direct interaction between membranes and cell wall matrix stabilizing the membrane structure. The main consequences of the down-regulation are: (11) stiffening of cell walls or reduction in the lignification process; (12) alteration in the cell wall-plasma membrane-cytoskeleton continuum; (13) alteration in AGPs synthesis and distribution; (14) decrease in their content by hormone $(\mathrm{H})$ stimuli. For further details about each mechanism see the main text.

protein-like regions where $\mathrm{PC}$ are a plant-specific family of proteins involved in copper transport and are required in different processes such as plant photosynthesis, plant development and stress response (Ma et al. 2011). Xylogen-like AGPs are chimeric AGPs characterized by an AGP domain and a plant non-specific lipid-transfer protein (nsLTPs). Xylogen is a glycoprotein which is involved in the differentiation of tracheary element (TE) and in local intercellular communication (Motose et al. 2001).

The presence of AGPs has been reported in various organs such as leaves, stems, roots, floral parts and seeds with a spaceand time-regulated expression (Fincher et al. 1983; Nothnagel 1997). Regardless of tissue, AGPs are generally found in the plasma membrane, cell walls or into intercellular spaces but also within intracellular, multivescicular bodies. The finely-tuned and organ-tissue and cell-specific expression of AGPs makes these molecules as markers of cellular identity and fate (Pennell et al. 1989, 1991; Pennell and Roberts 1990). AGPs are also involved in cellular growth and development (Van Hengel and Roberts
2002, 2003), cell expansion (Lee et al. 2005; Yang et al. 2007) programmed cell death (PCD) (Gao and Showalter 1999), hormone responses (Park et al. 2003) and signalling (Schultz et al. 1998). A role of AGPs has also been described for plant reproduction, from pollen grain development (Pereira et al. 2006) to pollen tube growth and guidance inside the female tissue (Cheung et al. 1995), as well as for stigma receptivity (Losada and Herrero 2012). In addition to this, AGPs are thought to be involved in the response pathway of plants against different kind of biotic and abiotic stresses spanning from water deficiency to heat stress to bacterial infection (Gaspar et al. 2004; Yang et al. 2005; Mareri et al. 2016). In the most of cases, it is not clear whether such modifications are either part of the cell damages or direct/indirect consequences of the cell response.

The purpose of this manuscript is to critically organize and re-elaborate the available knowledge on the relationship between abiotic/biotic stresses and AGPs. An in-depth knowledge of AGP biology under stress conditions is a valuable step forward 
in understanding whether AGPs are target molecules for stress or whether they are involved in resistance mechanisms. Detailed analysis of the effects of such stressful conditions on AGPs can also provide additional information about their functions. The review is divided into two main sections, one for abiotic stresses (low and high temperature, drought, high salinity, flooding/ hypoxia/anoxia and metal deficiency/toxicity) and one for biotic stresses (viruses, bacteria, fungi and nematodes). Finally, a table summarizes all the information to produce a quick overview of variations in AGP levels.

\section{AGPs and abiotic stresses}

\section{Low and high temperature}

Temperature is among the most important environmental factors that control plant development, growth and yield. Rapid or otherwise relevant changes of temperature represent stressful conditions for plants and are therefore harmful in terms of growth, reproduction and crop yield. During their evolution, plants have developed several structural modifications and biological processes to rapidly acclimatize and counteract temperature variations. Among the several molecules taking part in the response of plants to temperature stress, both cold and heat stress, AGPs are likely candidates in view of several reports.

Cold stress seems to differentially regulate the expression of AGP genes. A genome-wide study of the AGP gene family in rice (Oryza sativa L.) showed that cold treatment caused the up-regulation of some AGP genes (OsAGP3, OsAGP24 and OsAGP20) and the down-regulation of others (OsFLA1 and OsFLA4). Interestingly, while some AGP genes were similarly regulated by other stresses (OsAGP3 and OsAGP24 were also up-regulated by salt and drought stresses), OsAGP20 was up-regulated by cold and down-regulated by salt and drought stresses (Ma and Zhao 2010). The up-regulation of OsAGP20 could be explained considering the Kawaguchi's study, which shows that a tetrasaccharide with similar structural characters to the sugar chains of AGPs might play an important role in both the development of anthers and its response to chilling. Therefore, OsAGP20 might be used as a potential source of tetrasaccharides in response to cold stress (Kawaguchi et al. 1996). Interestingly, the expression level of OsAGP20 was also modulated by hormone treatment because abscisic acid (ABA) decreases its

40 expression level while giberellic acid (GA) increased the level of AGP20. In this regard, a study in barley aleurone cells showed that b-Glucosyl Yariv reagent (a cytochemical reagent able to interfere with the functions of AGPs) inhibits GA signalling, indicating that AGPs are involved in the perception of stimuli causing defence responses (Mashiguchi et al. 2008). In wheat (Triticum aestivum), most AGPs were down-regulated by cold stress while some members were up-regulated in root tissues. More specifically, the expression of TaFLA9 and TaFLA12 genes was enhanced by cold treatment with accumulation of mRNA in root tissues of plants acclimated for 6 days at $4{ }^{\circ} \mathrm{C}$. Interestingly, with longer period of acclimation, mRNA level returned to normal ranges. $\mathrm{A}$ similar pattern was also found for TaFLA14 and TaFLA18 genes (Faik et al. 2006). Considering that FLAs are hypothesized to mediate cell-cell adhesion (Clout et al. 2003; Johnson et al. 2003), the cold-enhanced expression of FLAs could be used to strengthen the protein interaction mechanisms and, consequently, to provide a way of facilitating cell-cell communication. In addition to this, it is interesting to note that all the above-mentioned FLA genes belong to group VI, the closest to group VII. In Arabidopsis, the group VII includes AtFLA11, which is involved in secondary wall formation (Brown et al. 2005). This result suggests that the up-regulation of specific FLA members could be related to cell-cell communication and cell wall thickening.

Other non-standard AGPs might play similar protective functions during cold stress. An additional study supporting the involvement of AGPs in low temperature tolerance showed that during the cold hardening of winter wheat (Triticum aestivum L., cv. Mironovskaya 808) two lectins, namely the 37- and 69-kD lectins, transiently appeared. The transient appearance of these lectins, later identified as AGPs, might trigger plant cell defence responses to cold stresses (Garaeva et al. 2006). In particular, authors reported that wheat enhanced the synthesis of lectins (including 37-kD and 69-kD lectins) during the first phase of hypothermia. After six days of hardening the content of protein drastically dropped down indicating that the adaptation process was reached. These results lead to the suggestion that lectins participate in cold stress signalling. As shown in Arabidopsis thaliana, cold stress seems to induce the activation of phospholipase $D$ and $C$ leading to the cleavage and release of AGPs from the plasma membrane into the cell wall and cytoplasmic ambient (Ruelland et al. 2002). It is also interesting the widely accepted idea that cell wall AGPs might contact specific receptors located in the plasma membrane thus forming complexes that facilitate the interaction between molecules of the signalling pathways (Oxley and Bacic 1999; Baluška et al. 2003). In cotton (Gossypium hirsutum L.), a non-classical cell wall-located AGP, GhAGP31, was found to be developmentally regulated in roots and to gradually increase its expression following cold stress treatment with the highest expression level after $12 \mathrm{~h}$ at $4{ }^{\circ} \mathrm{C}$. Freeze tolerance was also detected in transgenic Arabidopsis plants expressing GhAGP31: under cold stress treatment, all tested transgenic lines displayed high levels of GhAGP31 together with remarkably longer root and higher level of proline content while COR genes seemed to be induced in both transgenic and wild-type plants (Gong et al. 2012). Reasonably, this specific non-classical AGP might ameliorate the damages induced by cold stress at the level of roots, where the most dramatic effect caused by freezing is the reduced ability of such organs to absorb water and solutes. Still in cotton, a hybrid proline-rich protein (HyPRP) (which could be hypothetically the core polypeptidic chain of AGPs) was found to be upregulated in roots by cold stress, as well as by salt and osmotic stress. Interestingly, plants overexpressing HyPRP acquired tolerance against cold and salinity stress (Qin et al. 2013). The ability of this specific protein to protect plants against two different stresses reinforces the concept that plants sense cold stress as the inability of absorbing water, the same negative effect also caused by salinity stress. In banana (Musa spp.), several AGPs accumulated preferentially in the root and leaves of freeze tolerant genotypes whereas they decreased in sensitive genotypes subjected to cold stress (Yan et al. 2015). Particularly, cell wall AGPs were differentially modified in banana tissues under low temperature stress with specific AGPs being important for banana tolerance to strong and mild low-temperature stress. This differential regulation of AGP genes under low-temperature is consistent with the above reported studies. Interestingly, a characteristic distribution of 
AGPs in different cell types of low temperature-treated banana leaves was also reported with higher level of AGPs in phloem and mesophyll cells. In addition to this, different tissues seem to have a different kinetics of accumulation of AGPs: banana roots accumulate AGPs faster that banana leaves.

The molecular mechanism underlying AGP-dependent freeze tolerance is still unknown. Generally, cold stress induces the upregulation of specific AGPs. The increase in AGP level under low temperature treatment could be explained as an adaptation

10 of cells to such a stressing condition that threats plant membrane fluidity, macromolecular conformation and nutrient and water uptake. Based on reported studies, we suppose that the enhanced expression and accumulation of AGPs might provide a more suitable environment for cell-cell interaction or for local

15 strengthening of the cell wall. In addition, AGPs can modulate the cold signalling pathway leading to the activation of specific genes directly involved in low temperature tolerance.

Like for low-temperature stress, also high-temperature seems to alter AGP expression level and distribution. Evidences in tomato (Solanum lycopersicum L.) plants showed that high temperatures transiently down-regulate the mRNA for AGPs in stems ( $\mathrm{Li}$ and Showalter 1996). The recovery period, necessary to restore the normal gene expression, varied depending on the severity and duration of heat stress: longer and acuter was the stress, more time was necessary to reaccumulate AGPs. In addition, tomato GRP gene, which codes for a cell wall protein, was up-regulated by heat shock acclimation and its mRNA level rapidly recovered. In coffee leaves (Coffea arabica L.), the chemical profile of cell wall polymers was profoundly affected by heat stress treatment. Particularly, Lima et al. (2013) reported an increase in arabinose and galactose content under heat stress condition. On the contrary, the content of mannose, glucose, uronic acid, rhamnose and fucose decreased. The authors suggested that the increase in the main component of AGP carbohydrate moieties could be explained by considering the behaviour of resurrection plants in which the high content of AGPs in leaf cell wall contributes to the ability of these plants to survive when they undergo repeated periods of desiccation and rehydration. In this regard, it is important to point out that type II arabinogalactans can be evolved in

40 the rigidification of cell wall by oxidative crosslinking as reported by Seifert and Roberts (2007) thereby enabling cells to reduce the loss of water caused by high temperatures.

Not only in vegetative tissues but also in reproductive tissues AGPs seem to be altered. Mareri et al. (2016) showed that even

45 a short episode of high temperatures $\left(3 \mathrm{~h}\right.$ at $42^{\circ} \mathrm{C}$ ) can dramatically alter AGP level and distribution in pistils of tomato plants (Solanum lycopersicum cv Micro-Tom). Pistil structures were not equally damaged by heat stress with stigmas and ovules being the most affected parts of the pistilar structure. Moreover, the severity of stress seemed to be linked to the developmental stage at which heat stress was applied: pistils receiving the stress 10 days before anthesis (DBA) were less compromised than pistils receiving the stress 5 DBA. It could be possible that those tissues receiving the stress at the beginning of their development (10DBA) have more time to restore the physiological expression of AGPs while those tissues already developed at the time of stress are not fully able to restore the normal condition. Taken together, these results suggest that heat stress profoundly affects AGP expression and distribution in a tissue-specific manner. Indeed, different tissues show a different AGP pattern under stress condition. Generally, stems and reproductive tissues down-regulate AGP expression ( $\mathrm{Li}$ and Showalter 1996; Mareri et al. 2016), while leaf tissues seem to increase AGP content (Lima et al. 2013). We can hypothesize that cells of organs (such as leaves), which are more susceptible to water loss, need to increase the thickness of their cell walls to limit further water loss. For this purpose, plants could increase the synthesis of specific molecules, including AGPs. In this context, AGPs would increase the stiffness of the cell wall and, therefore, limit the loss of water caused by heat stress. Conversely, organs or tissues less inclined to water loss (e. g. stems) or not directly exposed to the atmosphere (e. g. ovules) do not need to increase AGP production (this could only represent a loss of energy).

\section{Drought}

Another limiting stress for plants is drought, especially in anticipation of future climate changes. Plants react in very different ways to the occurrence of this problem, from the closing of stomata to the synthesis of osmoprotectants up to structural changes derived from evolutionary processes, such as tissues or organs capable of storing water. An important physical barrier that limits water leakage during drought is the cell wall that can be widely altered in drought conditions, for example by deposition of specific polysaccharides that help maintaining the proper polymeric structure and avoid irreversible adhesion or collapse (Moore et al. 2008). In the moss Physcomitrella patens, 2-D electrophoresis analysis showed that many proteins changed their quantity in response to water stress. Among these, proteins with sequence comparable to AGPs were likely the most responsible for the mechanism of resistance, although their exact role is still not known. Authors reported that AGPs accumulate during the dehydration-rehydration cycle and that AGP level was 2-fold higher than in control condition (Cui et al. 2011). A possible explanation to this increase in AGP content is that AGPs form a "buffer zone" that prevents the direct interaction between membranes and cell wall matrix and, thus, stabilizes the membrane structure. Interestingly, phospholipase D, the enzyme that controls the release of AGPs in stressful conditions, also accumulated throughout the dehydration-rehydration cycle indicating that AGPs are modulated by stressful conditions. In addition to classical AGPs, non-classical AGPs were reported to be involved in the response to drought stress and a cross-talk with hormones has also been suggested (Munnik et al. 2000; Ruelland et al. 2002). An example of non-standard AGPs, whose expression is differently modulated by drought, is the REPETITIVE PROLINE-RICH PROTEIN (RePRPS). RePRPs are proteins heavily glycosylated by arabinose and glucose residues; therefore, they differ from standard AGPs that contain arabinose and galactose. As reported in rice (Oryza sativa L.) RePRP appear to be associated with the plasma membrane of root cells in the elongation region. Tseng et al. (2013) reported that these proteins mediate the action of $A B A$ since $A B A$ induces an increase in their expression while overexpression of RePRPs reduces the elongation of roots, the same effect normally caused by $A B A$. Therefore, $R e P R P$ could be the mediators of the response induced by $A B A$ in the event of water stress. The cross-talk between AGP expression and $A B A$ has also been reported in another interesting study in rice. Expression studies indicated that drought induced the 
expression of several AGPs genes including OsAGP1, OsAGP15 and OSELA3 that were also up-regulated by ABA treatment. This evidence could indicate that they are $A B A$-induced genes and that are involved in the ABA-mediated stress response pathway. This hypothesis is supported by the behaviour of the atagp30 mutant, which is characterized by suppression of ABA-induced delay in germination and by altered expression of some ABAregulated genes (Van Hengel and Roberts 2003). Like animal proteoglycans, AGPs could also modulate hormone activity in

10 response to adverse conditions. Still in rice, analysis with subtractive cDNA libraries and differential protein expression analysis revealed different genes expressed in drought-resistant or drought-sensitive genotypes, thus leading to the identification of many genes involved in drought response. Genes expressed exclusively in tolerant genotypes were generally related to maintaining turgor pressure and cell integrity. Among them, a gene encoded for an AGP (Rabello et al. 2008). As with rice, also in the Arabidopsis thaliana model plant, among the genes differently regulated by drought, there are some genes related to the cellular structure, such as three pectin esterase, a pectin methyl esterase and an AGP (Seki et al. 2002). Hypothetically, the increase in these proteins including AGPs could help preserving an adequate water level in the cell wall or could help maintaining a proper cell wall structure in case water falls below a critical level.

Another possible mechanism of action of AGPs could rely on the activation of specific deglycosylation enzymes that lead to the release of polysaccharide chains. The increase content of oligosaccharides might result in the increase in the intracellular osmotic pressure, reducing the speed of dehydration. Additional studies analysed the effects of drought on specific AGPs that are related to cell wall lignification in xylem tissue. Particularly, Yang et al. (2005) analysed AGP-like genes from differentiated pine xylem and their expression was examined in several tissues (earlywood, latewood, drought-stressed and well-watered roots, in vitro cultured cells induced for lignification). Different AGP-like genes showed varying expression patterns in different conditions, suggesting different functions for each pine AGP. Under drought conditions, AGPs showed a decrease level in roots tissue which has been interpreted as a stress signal. Similarly, PTGRP (proline-, threonine-, and glycine-rich protein) isolated from wild tomato (Lycopersicon chilense) appeared to be down-regulated by water stress by about 5-10 times compared to plants regularly watered. Specific antibodies have shown that in regularly-watered plants PTGRP was localized in the membranes of xylem pits and in disintegrated primary walls. In plants subjected to drought, the amount of protein was greatly reduced while in rewatered plants the distribution pattern was similar to that of regularly-watered plants (Harrak et al. 1999). These data indicate that the levels of available water may change the expression pattern of AGP genes, although in this specific case PTGRP does not appear to be required during water stress.

All these data suggest that there is a consistent variability in the possible functions of AGPs under drought stress condition and that it is still not possible to make a clear assumption. The response to drought condition appears to depend on the species and to be mainly linked to cell wall modifications. Some model cells have been proven useful in understanding how the cell wall can be altered when the turgor pressure changes under drought condition. From this point of view, the pollen tube is an excellent model of study. Changes in turgor pressure induced by hypoosmotic or hyperosmotic growth media have considerable effects on the type of polysaccharides and glycoproteins deposited in the cell wall. Pollen tubes grown in hypoosmotic medium can undergo an enlargement due to an excessive influx of water; apparently, this cellular expansion is offset by increased local deposition of AGPs and acidic pectins (Li et al. 1996). This substantially affects the process of pollen tube growth, which is no longer oscillatory but continuous (Biagini et al. 2014). Therefore, in the specific case of pollen tubes, an incorrect flow of water leads to a modification of the cell wall components to stabilize the physical structure of cell walls.

\section{Flooding and hypoxia/anoxia}

Flooding is a condition that causes a series of sequential stresses to plants. The presence of a large amount of water, for example during flooding, can lead to a series of physiological and molecular consequences, such as dilution of solute content (nutritional deficiency) or decrease in oxygen diffusion (especially in the underground organs). Flooding stress is therefore closely related to hypoxia/anoxia stress. Plants can survive by modifying some metabolic processes such as switching from respiration to fermentation (Loreti et al. 2016) or the distribution of sucrose (Santaniello et al. 2014). Like in other stress conditions, the cell wall is a barrier that can adapt to the new circumstances to mitigate the deleterious effects of flooding. Some reports indicated that the cell wall can be heavily modified under flooding conditions, for example by changing (often decreasing) the content of cellulose or by increasing the content of hemicellulose or amorphous cellulose, or by increasing the content of lignin. Most likely, this changes the water retaining capacity of the cell wall. These changes may also have important impacts in the process of cell morphogenesis; a cell wall differently enriched in cellulose may have a higher degree of expansion, which may be important for faster cell growth as occurs when plants are submerged by flooding (Le Gall et al. 2015).

Flooding and the related stresses hypoxia and anoxia cause extensive reprogramming of gene expression. A relatively recent study in soybean (Glycine max L.) evaluated the alterations of the endoplasmic reticulum (ER)-enriched fraction under flooding condition. Interestingly, Komatsu et al. (2012) found that the mRNA levels of 14 genes (encoding proteins predicted to be localized in ER) were differently regulated under flooding treatment. Particularly, the mRNA level of 3-ketoacyl-CoA reductase 1, the enzyme that catalyses the elongation of acyl-CoA from malon$\mathrm{yl}-\mathrm{Co} A$ when NADPH is present, was up-regulated while the levels of 10 genes, involved in stress response, cell wall and DNA repair and hormone metabolism were down-regulated within 1 day under flooding conditions. Among the down-regulated genes, FLA2 and methyltransferase (PMT2) were reported. The down-regulation of FLA2 and PMT2 genes has been linked to a reduction in the lignification of cell wall under flooding condition. In a previous study, Komatsu et al. (2010) reported that the lignification of roots and hypocotyls was suppressed under flooding condition. Particularly, the reduction of reactive oxygen species (ROS) levels and jasmonate biosynthesis as induced by flooding caused the decrease in several cell wall-related proteins including FLA2 and 
methyltransferase PMT2 and, thus, the suppression of the lignification process. In a recent study, a flooding tolerant mutant line and an ABA-treated soybean line were studied to unravel their resistance mechanisms under both the initial and continuous flooding treatment. In both lines, polygalacturonase inhibitor-like and expansin-like B1 proteins, usually used as markers of flooding injuries in soybean seedlings, showed a specific regulation: as expected, polygalacturonase inhibitor-like protein was up-regulated more than 100-fold in both mutant and ABA-treated lines while expansin-like B1 was not apparently affected by flooding (Yin et al. 2016). These results suggested that the integrity of the soybean cell wall is stabilized by polygalacturonase inhibitor-like proteins under flooding condition. We could also expect that the expression of FLA2 and methyltransferase PMT2 is enhanced by

15 flooding treatment in both the mutant and ABA-treated lines. Additional evidences supporting the role of FLA2 in the lignification of cell wall come from the study of other species subjected to different abiotic stresses, such as cold and salt stresses, where the lignification of cell wall represents an important response to overcome the stress. For example, in Populus trichocarpa root tissue, 18 FLA genes, including FLA2, were specifically induced by salt stress (Zang et al. 2015). These evidences suggest that FLA genes are target of flooding stress rather than molecules actively involved in defence mechanisms. Anyway, the available data are still poor, and more studies are needed to clarify this hypothesis.

Hypoxia and anoxia are reported to differently regulate mRNA levels of AGPs encoding genes in tomato fruits (Solanum lycopersicum). Generally, hypoxia treatment caused a decrease level of some AGPs (SIAGP1, SIAGP2 and SIAGP4) and a constant expression of others (JIM8-bound AGPs) while anoxia treatment caused up-regulation of specific AGP genes (SIAGP4 and JIM8bound AGPs) and down-regulation of others (SIAGP1 and SIAGP2) (Fragkostefanakis et al. 2012). The constitutive and enhanced expression of specific AGPs in both hypoxia and anoxia treatments would suggest an involvement of AGP proteins in the adaptation process. The study of the influence of hypoxia/anoxia on AGPs has also been extended on enzymes that regulate AGP biosynthesis and modification. Attention was focused on prolyl-4-hydroxylases (P4H). $\mathrm{P} 4 \mathrm{H}$ is an enzyme that catalyses the hydroxylation of pro-

40 line residues in hydroxyproline-rich glycoproteins (HRGPs), the major class of cell wall proteins that includes AGPs, extensins and proline-rich proteins (Vlad et al. 2007). Authors found that AtP4H members were differently regulated by hypoxic and anoxic treatments and that the 22 HRGPs identified in silico (including AGPs and extensins) were differently regulated by anoxia. Among the AtP4Hs analysed, only AtP4H3 was induced under both anoxia and hypoxia treatments in roots while only AtP4H4 was induced under the hypoxia treatments. The above-mentioned AtP4H would be involved in the synthesis of HRGPs as induced by anoxia and hypoxia. Considering that HRGPs are glycoproteins involved in cell wall stability, the up-regulation observed under hypoxia/anoxia can be necessary for the normal plant physiology.

\section{Salinity stress}

Another major abiotic stress that plants can suffer during their lifecycle is salt stress, which is mainly due to deposition of oceanic salts and erosion of rocks (Munns and Tester 2008). The consequence of salt stress is the reduction of the osmotic potential of the soil, and thus the reduction in water availability, and the increase in ionic forms within the cell cytoplasm, capable of inhibiting enzymes' activity and the corresponding biochemical pathways (Shabala and Munns 2012). The involvement of AGPs in salt stress is linked to the evidence that AGPs are implicated in cell expansion. This has been demonstrated in tobacco (Nicotiana tabacum L.) where cultured cells adapted to $\mathrm{NaCl}$ exhibited a reduced rate of cell enlargement and a decreased cell-wall extensibility. These cells were deficient in AGPs on the plasma membrane while non-adapted tobacco cells showed a very high level of AGPs on the plasma membrane (Zhu et al. 1993). On the contrary, Lamport et al. (2006) observed a massive up-regulation of AGPs in salt-stress tobacco cells: a release rate of AGPs up to 6 times higher was observed in salt-adapted cells indicating an important increase rate of AGPs diffusion through a much more highly porous pectic network. Similarly, salt adapted embryogenic suspension cultures of Dactylis glomerata L. indicated that AGPs are mostly localized in the growth medium of salt treated cultures (Zagorchev and Odjakova 2011). These findings suggest at least two hypotheses. First, AGPs may act as plasticizers under salt stress; second, the release of different AGPs could be viewed as a response to salt stress condition because AGPs are important molecules related to both stress adaptation and cell-cell signalling. The mechanisms regulating the release of AGPs under salt stress condition is still unclear and may hypothetically require the activation of both an inner signal (detached GPI anchor) and of outer signals (activation of cell-surface phospholipase C or D to cleave the GPI anchor). In support of this hypothesis, Munnik et al. (2000); Ruelland et al. (2002); Zhu et al. (1993) reported the rapid activation of phospholipases by hyperosmotic and cold stress.

The presence of AGPs was also described in Brassica oleracea where the xylem sap contained a total concentration of AGPs of $5.2 \mathrm{mg} / \mathrm{mL}$ (Fernandez-Garcia et al. 2011). In agreement with Lamport et al. (2006), who described an increase in AGP levels in the growth media of salt-adapted cell cultures (tobacco BY-2, tomato, acacia and Arabidopsis), Brassica oleracea seemed to accumulate AGPs after $24 \mathrm{~h}$ of salt treatment. Immunolocalization of AGPs revealed that they were localized in the secondary cell walls of xylem elements where their abundance was reduced in salt treated plants. These evidences suggest that AGPs are actively secreted by specialized cells of xylem elements and accumulated in the xylem sap but the reduced presence in the secondary cell wall indicates a reduction in its plasticity. In Populus, 18 FLAs were expressed in root tissues; PtrFLA2/12/20/21/24/30 were significantly induced at different time points: the results showed that four genes (PtrFLA2/12/20/30) were upregulated after $12 \mathrm{~h}$ of $\mathrm{NaCl}$ stress, and the expression pattern exhibited an upward trend after $24 \mathrm{~h}$ of $\mathrm{NaCl}$ stress (Zang et al. 2015). It is conceivable that the large carbohydrate chain serves as a source for oligosaccharides that, after deglycosylation, increase the intracellular osmotic pressure and decrease the speed of dehydration during osmotic stress; however, this could be still only one of the many roles of AGPs in plant stress response and probably not the only one. Additional explanations to the increase in FLA genes arise from the evidence that FLA proteins are involved in cell-cell communication, in the lignification of cell-wall, in the secondary wall formation (Brown et al. 2005; MacMillan et al. 2010) and fibre development (Liu et al. 2008). The observed up-regulation of FLA 
genes could represent a response to salt stress: a more efficient communication between cells, an increase in cell wall lignification and secondary wall formation are essential for an optimal response. As for cell wall lignification, in tomato (Solanum lycopersicum) Neves et al. (2010) concluded that $\mathrm{NaCl}$ stress promoted cell wall lignification of vascular tissue and that the deposition of lignin is an adaptation during salinity stress. In addition to this, S-adenosyl-I-methionine synthase (SAM), the same enzyme found to be down-regulated under flooding stress, was up-reg-

10 ulated under salt stress. Similarly, the increased activity of SAM was found to be correlated with a greater deposition of cell wall in vascular cells under salinity stress in tomato (Sánchez-Aguayo et al. 2004).

More recently, (Lamport and Várnai 2013) reported that AGPs

15 serve as flexible storage molecules for $\mathrm{Ca}^{2+}$ suggesting that AGPs are actively involved in signalling events activated by stress because the increase in $\mathrm{Ca}^{2+}$ is fundamental for cell signalling (Plieth 2012; Osakabe et al. 2013). Finally, carbohydrate chains can be hydrolysed by chitinases and the resulting oligosaccharides could also play possible signalling function as suggested during somatic embryogenesis (Van Hengel et al. 2002). As plant chitinases are also involved in plant stress response (Grover 2012), it would not be unexpected that the same process occurs also in response to unfavourable environmental conditions. Ultimately, the role of AGPs during salt stress can be multifaceted, from the stiffening of cell walls (when AGPs decrease), to the activation of signalling mechanisms (by releasing extracellular AGPs), to the accumulation of soluble carbohydrates in the cytoplasm to decrease water loss.

\section{Mineral deficiency and toxicity}

Mineral nutrition is essential for plant life and nutritional disorders occur every time plants experience excess or deficiency of one or more elements, which may be due to human activity but also to infestations of diseases, insects and weeds. Among all the abiotic stresses considered in this review, mineral deficiency/ toxicity is the hardest one to analyse. Indeed, there are very few studies aimed to explore the effects of minerals on AGP biology. This is an important lack for our knowledge and the present gap needs to be filled in the next future. The following text discusses the only examples of nutrition/toxicity deficiencies available in literature concerning boron, copper, cadmium and chromium.

Boron is an essential nutrient for plant growth and development (Camacho-Cristóbal et al. 2011). In Arabidopsis cells, boron deficiency caused the down-regulation of AGPs. Particularly, data from microarray analysis showed that 5 AGP genes were down-regulated by boron deficiency. Three of them, AtAGP13, AtAGP14 and AtAGP22 were AG-peptides and two, AtFLA9 and AtFLA13, were fasciclin-like AGPs. Together with the down-regulation of AGP genes, boron deficiency caused a decrease in mRNA level of other genes such as expansins, pectin methylesterases, polygalacturonases, and pectate lyases involved in the maintenance of cell-wall stability (Camacho-Cristóbal et al. 2008). It was suggested that AGPs may be potential candidates at the cell surface to mediate signal transduction by creating continuity between cell wall, plasma membrane and cytoskeleton (Sardar et al. 2006). Some authors suggested that the rapid decrease in the expression of AGP genes under boron deficiency could alter the cell wall-plasma membrane-cytoskeleton continuum. In addition to this, boron is also supposed to have a possible role in cytoskeleton structure and associated processes (Yu et al. 2001, 2003). Consequently, boron deficiency could severely compromise the cell wall structure (directly or indirectly) with negative impacts on plant functionality.

For copper, there are no direct evidences indicating the involvement of AGPs on abiotic response. Nevertheless, worth of note is that among the genes specifically expressed in copper-treated pith explants of N. glauca, AGPs were found (Taddei et al. 2007). We can only speculate that plants can use the increase quantity of AGPs as a buffer of copper ions in excess. Indeed, as reported by Grishchenko et al. (2004) copper ions are able to constitute complexes with arabinogalactans in a wide $\mathrm{pH}$ range (from $\mathrm{pH} 5.0$ to 12.5 ).

Among non-essential elements, cadmium is one of the most toxic for plants. In order to limit the damages caused by cadmium toxicity, plants can use several strategies such as the formation of cadmium-ligand complexes, where ligands can be phytochelatins (PCs) and glutathione (GSH) then transported to the vacuoles, or the use of metallothioneins (MTs) (Cobbett 2000). Another important response, especially during the early phase of cadmium toxicity, is the total reprogramming of cell wall metabolism. In this regard, Yang et al. (2015) described the thickening of cell wall after plant exposure to $50 \mu \mathrm{M}$ cadmium for 1 month. Particularly, a notable increase in callose deposition was observed. While callose synthase genes and all genes related to lignin biosynthesis and cell wall thickening were almost up regulated, cellulose synthase genes, xyloglucan endotransglycosylase and AGP genes were down-regulated after cadmium treatment (Parrotta et al. 2015). Like for other stresses, such as salt stress, the lignification of cell wall represents an important response to extern threat. In cadmium-resistant Salix matsudana Koidz, cadmium induced a different response in the tissues of leaves and roots. In root tissues, up-regulation of genes involved in the deposition of callose and in cell wall thickening was observed, whereas in leaf tissues there was a large reprogramming of the synthesis of secondary metabolites and of signalling related to biotic stress. In this regard, AGPs seemed to be down-regulated in both leaves and roots (Yang et al. 2015).

Another element that can be toxic for plant is chromium (Shanker et al. 2005). Negative effects of chromium on plant development and growth include morphological, physiological and metabolic alterations. Plant reproduction seems to be a target of chromium toxicity and several reports indicate that high concentrations of this element compromise pollen viability (Calzoni et al. 2007), germinability and shape (Speranza et al. 2007). In kiwifruit pollen tubes (Actinidia deliciosa var. deliciosa), AGPs were reported to be target of cadmium stress. Cadmiumtreated pollen tubes showed aberrant morphology with alteration in AGP distribution. AGPs were concentrated in some areas of the cell wall and almost absent in others, while vacuoles were oversized and their content cross-reacted with JIM8 and JIM13 antibodies. Authors also reported a decrease in the content of polysaccharides in cell walls together with a profound alteration in callose deposition (Speranza et al. 2009)

These results suggest that the response to mineral deficiency/ toxicity is dependent on a large number of factors including the nature of element, its concentration, and its function in addition 
$8 \fallingdotseq$ L. MARERI ET AL.

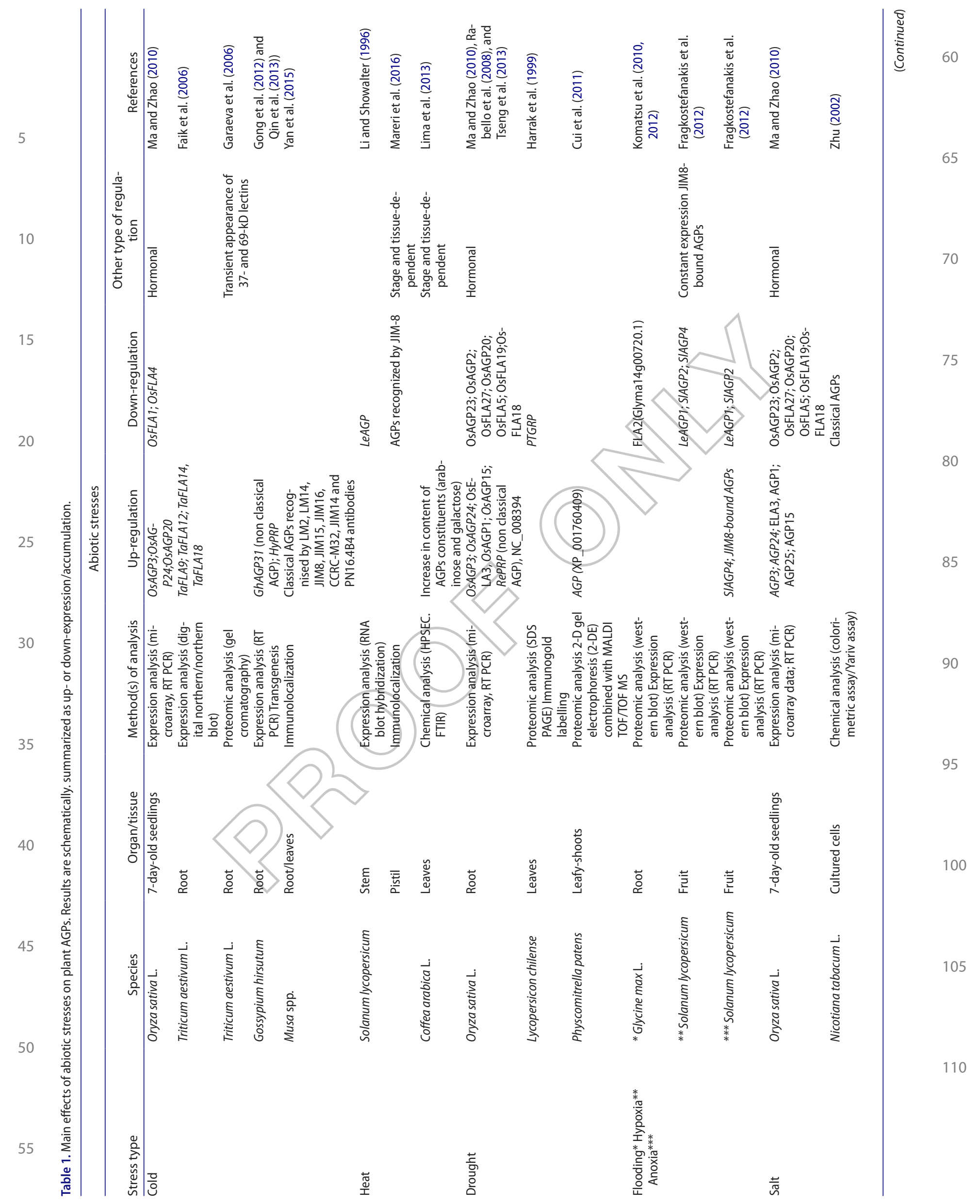




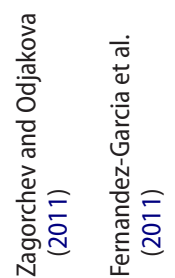

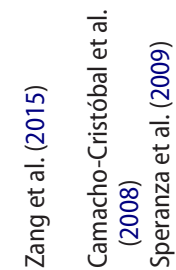

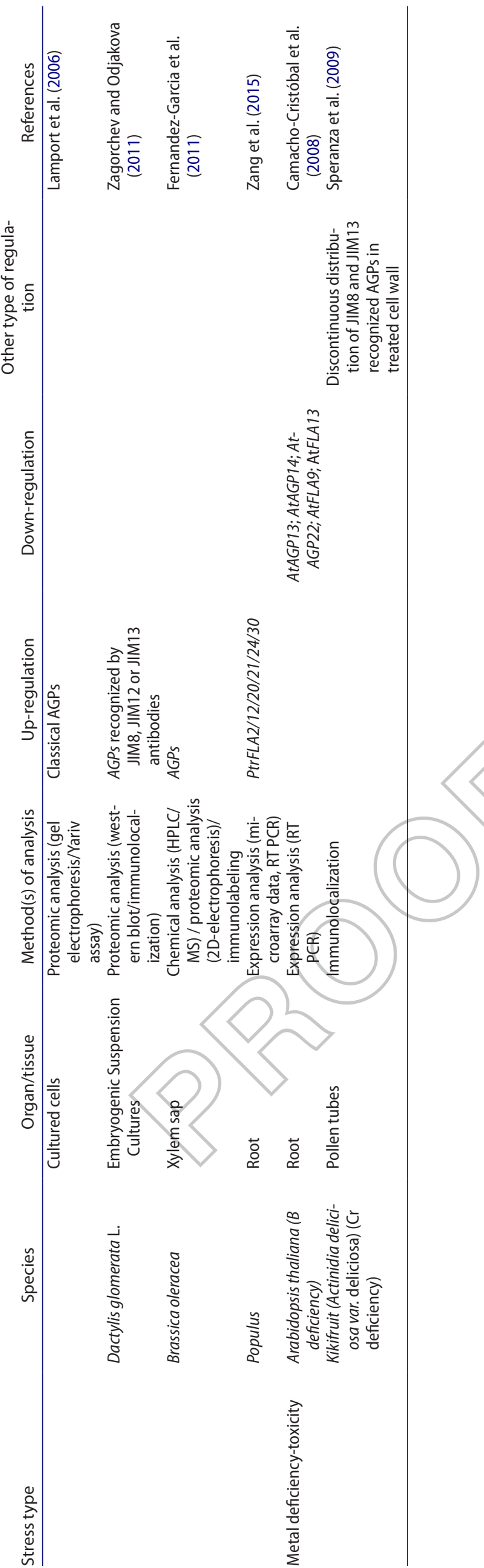

to the tissue/organ considered. For this reason, more studies are need.

\section{AGPs and biotic stresses}

Plants, like all living organisms, are subjected to infections caused by different classes of pathogens, including bacteria, fungi, viruses and nematodes. Plants do not possess a developed immune system such as vertebrates but, during their evolution, they have acquired the ability to defend against pathogens through a series of preventive or induced defence mechanisms (Jones and Dangl 2006; Burdon and Thrall 2009). While the general prevention mechanisms are based on the release of previously stored substances of different chemical nature, the induced defensive mechanism requires the recognition of the pathogen through receptor proteins (generically classified as $\mathrm{R}$ proteins) and effector molecules released by the pathogen. Only a limited number of studies investigate the involvement of AGPs in the relationship between plants and pathogens. It is therefore a priority to define the role of AGPs, especially if they act as either defence or signal molecules because information could be used to design efficient strategies aiming at controlling pathogen infections.

In the last years, AGPs have been recognized to play an interesting role in plant microbe interaction. The function of AGPs during plant-microbe interactions has been mainly studied in root, where the first contact between soil pathogens and plants occurs. Many studies reported that AGPs are involved from the recognition between root cells and microbes to the building of infectious structures passing by root colonization (Harrison 1999; Gage and Margolin 2000). The role of AGPs in the recognition process has been elegantly demonstrated by rat 1 mutant, an Arabidopsis mutant for AGP17 gene. Rat1 was not able to be infected by Agrobacterium tumefaciens and also wild-type plants, treated with Yariv reagent, showed a reduction in the frequency of transformation. When rat 1 mutants were complemented with AGP17, they restored the wild-type phenotype (Gaspar et al. 2004). An additional proof of the involvement of AGPs in recognition and attachment of rhizobia to root surface comes from Vicré et al. (2005), who demonstrated that, when Arabidopsis root cells were pre-treated with Yariv reagent, Rhizobium sp. decreased its ability to colonize them. An additional proof that AGPs are involved in microbe recognition and attachment consisted in the evidence that specialized root cells [root cap border cells (BCs) and border like cells (BLCs)] are highly enriched with AGPs (Vicré et al. 2005; Durand et al. 2009; Cannesan et al. 2012). Furthermore, these cells also secrete and release AGPs within rhizosphere (Vicré et al. 2005; Durand et al. 2009; Ma et al. 2010; Xie et al. 2012). An interesting study, (Vicré et al. 2005) showed that an Arabidopsis mutant unable to form BLC cells, release BCs and that BC cells produced an abundant and thick secretion, called "BC biofilm" mainly composed of AGPs and pectic xylogalacturonan (XGA) (Driouich et al. 2010). This matrix was supposed to be a form of plant defence: XGA component is not easily degraded by microbial pectin-hydrolyzing enzymes (Jensen et al. 2008) and AGPs can represent a sort of "adhesive glue" that holds together root cells (Durand et al. 2009; Driouich et al. 2010). In addition to their colloid properties, AGPs are thought to have antimicrobial properties. Cannesan et al. (2012) reported that, besides the structural 
Table 2. Main effects of biotic stresses on plant AGPs. Results are summarized on the basis of pathogen colonization/infection.

\begin{tabular}{|c|c|c|c|c|c|c|}
\hline \multicolumn{7}{|c|}{ Biotic stresses } \\
\hline Stress & Species & $\begin{array}{l}\text { Organ/ } \\
\text { tissue }\end{array}$ & $\begin{array}{l}\text { Analysis } \\
\operatorname{method}(\mathrm{s})\end{array}$ & Experimental evidences & $\begin{array}{l}\text { Other type of } \\
\text { regulation }\end{array}$ & References \\
\hline $\begin{array}{l}\text { Agrobac- } \\
\text { terium } \\
\text { tume- } \\
\text { faciens } \\
\text { Bacteria }\end{array}$ & $\begin{array}{l}\text { Arabi- } \\
\text { dopsis } \\
\text { thalia- } \\
\text { na }\end{array}$ & Root & $\begin{array}{l}\text { Mutagenesis } \\
\text { (rat1 mutant)/ } \\
\text { Yariv treat- } \\
\text { ment/ }\end{array}$ & $\begin{array}{l}\text { - Rat1 mutant (AGP17 defective): no infection } \\
\text { - Yariv reagent treatment: reduced root colonization } \\
\text { - Production of film with adhesive properties } \\
\text { - Inhibition of bacterial growth }\end{array}$ & $\begin{array}{l}\text { AGPs are involved } \\
\text { in plant-mi- } \\
\text { crobe interac- } \\
\text { tion }\end{array}$ & $\begin{array}{l}\text { Gaspar et al. (2004), Vicré et } \\
\text { al. (2005), Driouich et al. } \\
\text { (2010), and Cannesan et al. } \\
\text { (2012) }\end{array}$ \\
\hline
\end{tabular}

differences of Brassica napus and pea (Pisum sativum), the cell wall in root cap cells of both species were highly enriched in AGPs. These AGPs seemed to inhibit the development and growth of the pathogenic oomycete Aphanomyces euteiches. The precise mechanism by which AGPs inhibit Aphanomyces euteiches is unknown but it has been shown that the AGP fraction purified from pea root cap cells of $B C s$, in addition to attract $A$. euteiches zoospores by chemiotaxis, also induced zoospore encystment. The zoospore encystment allowed avoiding plant infection by immobilizing zoospores at the periphery of the tip or in the surrounding environment. In addition to these evidences, AGPs could be also able to establish a mechanical barrier that prevents pathogens to infect plants. A chimeric class of AGPs called arabinogalactan protein extensins, AGPEs, seemed to have a prominent role in creating a physical barrier as suggested by Shailasree et al. (2004). Authors noticed that AGPEs were particularly abundant in the cell wall of a pearl millet (Pennisetum glaucum L.) known to be resistant to Sclerospora graminicola infection compared to the susceptible cultivar. AGPEs could create a network by their reciprocal cross-linking that represents a barrier impermeable to fungal hyphae and an anchorage for lignification. A possible role of AGPs in controlling the colonization of roots has been also reported. Experiments in rat1 Arabidopsis mutant suggested that AGPs modulate the content of salicylic acid (SA) and pathogenesis-related proteins 1 (PR-1) favouring the successful infection by Agrobacterium tumefaciens (Gaspar et al. 2004).

On the pathogen side, several reports showed that pathogens possess enzymes able to degrade cell wall AGPs as reported by Vanholme et al. (2009). Authors described a putative endo-1,4- $\beta$-galactosidase located in the cyst nematodes of the genus Heterodera. The presence of cell wall modifying enzymes, including an arabinogalactan galactosidase belonging to GHF53 enzyme family, was also reported for the nematode Pratylenchus coffeae (Haegeman et al. 2011). In addition to this, as demonstrated by Albert et al. (2006), some pathogens seem to induce the host to synthetize AGPs in the attachment site (attAGP). The synthesis of AGPs appears to be restricted to the infection site with a positive correlation between the level of AGPs and the straightness of attachment of the parasite to its host. On the contrary, Gilson et al. (2001) reported that NaAGP4 expression was reduced after infection with Botrytis cinerea spores. In this case, spores were applied on a limited portion of plant leaves but they probably induce a systematic response.

As far as we know, no evidences are available for AGPs during virus-plant interaction. Even if not directly related to plant-virus interactions, it is interesting to point out the use of AGPs as antiviral molecules. A relatively recent study conducted by Oliveira et al. (2013) have demonstrated that one specific pectic AGP purified from leaves of Stevia rebaudiana, the SSFK-10RM fraction, was characterized by antiviral activity against Herpes simplex virus type-1 (HSV-1) in vitro. Authors suggested that the higher degree of antiviral activity of SSFK-10RM could be linked to the high purity of the polysaccharide and its reduced cytotoxicity is caused by its shorter highly charged HG region. In addition to this, because of their high solubility and biocompatibility, AGPs have been proposed as potent carrier in amphotericin $B(A m B)$ formulation (Parveen et al. 2007).

\section{Concluding remarks}

AGPs are hydroxyproline-rich glycoproteins located at the cell wall-membrane interface. They are ubiquitous in the plant kingdom where they are reported to play different functions in both vegetative and reproductive tissues (Ellis et al. 2010). AGPs have been the subject of many studies because of their broad distribution and possible involvement in different cellular processes. Unfortunately, this led to a multitude of information very often not strictly connected to one another. Therefore, a plethora of studies describe the functions of AGPs in various physiological contexts but their specific involvement during biotic and abiotic stresses remains less investigated. As clearly shown in Table 1 and Table 2, there is a great heterogeneity in the studies investigating the involvement of AGPs under stressful conditions with studies carried out with different techniques and in different species, in different tissues and often considering particular classes of AGPs. Taking into account the heterogeneity of information of AGPs, it is not possible to reach a clear conclusion and definitely establish if AGPs are actors or spectators during stressful conditions. Anyway, the analyses of the available reports indicate that AGPs are strongly affected by stresses. Generally, for those stresses (e.g. cold and salt) that seem to induce an increase in some specific AGP class, up-regulation could be interpreted as a plant defence mechanism. Increased AGPs could contribute to cell wall rigidification and thickening (Seifert and Roberts 2007) and cell-cell communication (Brown et al. 2005). The improvement in cell-cell communication could be important for an efficient transmission of signalling while cell wall rigidification can help plant to avoid internal damages by creating a physical barrier. The increase in AGP content and, thus, of their carbohydrate moieties, can also be useful to regulate the intracellular osmotic pressure. Several reports also suggest that AGPs are involved in the signal transduction pathways that are responsible for the defence mechanisms: phospholipase $C$ and $D$ cleave the lipid raft of AGPs that are released from the plasma membrane into the cytoplasm (Oxley and Bacic 1999; Munnik et al. 2000; Ruelland et al. 2002; Baluška et al. 2003). On the other hand, some stresses (for example, those induced by heavy metals and heat) seem to negatively affect the expression of AGPs; reducing the number 
of such molecules could conceivably lead to important consequences on the function of the cell wall, and then of the plant cell. In addition to that, AGPs might also have a defensive role during plant-pathogen interactions due to their adhesive and antimicrobial properties. Figure 1 schematically summarizes the effects of stressing conditions on AGPs biology. A more intensive study on this issue could have a major series of repercussions because the understanding of plant-pathogen relationships is fundamental in the development of preventive/defensive techniques especially in agricultural species. It, therefore, required an increased effort of the scientific community in studying the role of AGPs during protection of plants from infection.

The present review can be a stimulus to continue the research on AGPs when plants grow under adverse environmental conditions. Indeed, analysis of the available literature gives us important and interesting cues for future investigations. There are still open questions that need to be better clarified. Among them: Which is the mechanism used by AGPs to counteract stress treatments? Which AGPs are fundamental for the acquisition of stress tolerance? In this regard, a useful approach could be the reverse genetics that identifies gene function by mutant analysis. Proteomic technologies could also be instrumental in analysing the AGP pattern in relation to the advancement stage of stress level. In fact, because of their peculiar chemical nature, AGPs can be purified and analysed in a relatively non-complex manner.

\section{Disclosure statement}

No potential conflict of interest was reported by the authors.

\section{References}

Albert M, Belastegui-Macadam X, Kaldenhoff R. 2006. An attack of the plant parasite Cuscuta reflexa induces the expression of attAGP, an attachment protein of the host tomato. Plant J. 48: 548-556.

Baluška F, Šamaj J, Wojtaszek P, Volkmann D, Menzel D. 2003. CytoskeletonPlasma Membrane-Cell Wall Continuum in Plants. Emerging Links Revisited. Plant Physiol. 133: 482-491.

Biagini G, Faleri C, Cresti M, Cai G. 2014. Sucrose concentration in the growth medium affects the cell wall composition of tobacco pollen tubes. Plant Reprod. 27: 129-144.

Borner GHH, Lilley KS, Stevens TS, Dupree P. 2003. Identification of glycosylphosphatidylinositol-anchored proteins in Arabidopsis. A proteomic and genomic analysis. Plant Physiol. 132: 568-577.

Brown DM, Zeef LAH, Ellis J, Goodacre R, Turner SR. 2005. Identification of novel genes in Arabidopsis involved in secondary cell wall formation using expression profiling and reverse genetics. Plant Cell 17: 2281-2295.

Burdon JJ, Thrall PH. 2009. Co-evolution of plants and their pathogens in natural habitats. Science 324: 755-756.

Calzoni GL, Antognoni F, Pari E, Fonti P, Gnes A, Speranza A. 2007. Active biomonitoring of heavy metal pollution using Rosa rugosa plants. Environ. Pollut. Barking Essex 1987(149): 239-245.

Camacho-Cristóbal JJ, Herrera-Rodríguez MB, Beato VM, Rexach J, NavarroGochicoa MT, Maldonado JM, González-Fontes A. 2008. The expression of several cell wall-related genes in Arabidopsis roots is down-regulated under boron deficiency. Environ. Exp. Bot. 63: 351-358.

Camacho-Cristóbal JJ, Rexach J, Herrera-Rodríguez MB, Navarro-Gochicoa MT, González-Fontes A. 2011. Boron deficiency and transcript level changes. Plant Sci. 181: 85-89.

Cannesan MA, Durand C, Burel C, Gangneux C, Lerouge P, Ishii T, Laval K, Follet-Gueye M-L, Driouich A, Vicré-Gibouin M. 2012. Effect of arabinogalactan proteins from the root caps of pea and Brassica napus on Aphanomyces euteiches zoospore chemotaxis and germination. Plant Physiol. 159: 1658-1670.
Cheung AY, Wang H, Wu HM. 1995. A floral transmitting tissue-specific glycoprotein attracts pollen tubes and stimulates their growth. Cell 82: 383-393.

Clout NJ, Tisi D, Hohenester E. 2003. Novel fold revealed by the structure of a fas 1 domain pair from the insect cell adhesion molecule fasciclin I. Structure 11: 197-203.

Cobbett CS. 2000. Phytochelatins and their roles in heavy metal detoxification. Plant Physiol. 123: 825-832.

Cui S, Hu J, Guo S, Wang J, Cheng Y, Dang X, Wu L, He Y. 2011. Proteome analysis of Physcomitrella patens exposed to progressive dehydration and rehydration. J. Exp. Bot. err296.

Driouich A, Durand C, Cannesan M-A, Percoco G, Vicré-Gibouin M. 2010. Border cells versus border-like cells: are they alike? J. Exp. Bot. 61: 38273831.

Du H, Simpson RJ, Clarke AE, Bacic A. 1996. Molecular characterization of a stigma-specific gene encoding an arabinogalactan-protein (AGP) from Nicotiana alata. Plant J. Cell Mol. Biol. 9: 313-323.

Durand C, Vicré-Gibouin M, Follet-Gueye ML, Duponchel L, Moreau M, Lerouge P, Driouich A. 2009. The organization pattern of root border-like cells of Arabidopsis is dependent on cell wall homogalacturonan. Plant Physiol. 150: 1411-1421.

Ellis M, Egelund J, Schultz CJ, Bacic A. 2010. Arabinogalactan-proteins: key regulators at the cell surface? Plant Physiol. 153: 403-419.

Faik A, Abouzouhair J, Sarhan F. 2006. Putative fasciclin-like arabinogalactanproteins (FLA) in wheat (Triticum aestivum) and rice (Oryza sativa): identification and bioinformatic analyses. Mol. Genet. Genomics 276: 478-494.

Fernandez-Garcia N, Hernandez M, Casado-Vela J, Bru R, Elortza F, Hedden P, Olmos E. 2011. Changes to the proteome and targeted metabolites of xylem sap in Brassica oleracea in response to salt stress. Plant Cell Environ. 34: 821-836.

Fincher GB, Stone BA, Clarke AE. 1983. Arabinogalactan-proteins: structure, biosynthesis, and function. Annu. Rev. Plant Physiol. 34: 47-70.

Fragkostefanakis S, Dandachi F, Kalaitzis P. 2012. Expression of arabinogalactan proteins during tomato fruit ripening and in response to mechanical wounding, hypoxia and anoxia. Plant Physiol. Biochem. 52: 112-118.

Gage DJ, Margolin W. 2000. Hanging by a thread: invasion of legume plants by rhizobia. Curr. Opin. Microbiol. 3: 613-617.

Gao M, Showalter AM. 1999. Yariv reagent treatment induces programmed cell death in Arabidopsis cell cultures and implicates arabinogalactan protein involvement. Plant J. Cell Mol. Biol. 19: 321-331.

Garaeva LD, Pozdeeva SA, Timofeeva OA, Khokhlova LP. 2006. Cell-wall lectins during winter wheat cold hardening. Russ. J. Plant Physiol. 53: 746-750.

Gaspar YM, Nam J, Schultz CJ, Lee L-Y, Gilson PR, Gelvin SB, Bacic A. 2004. Characterization of the Arabidopsis lysine-rich arabinogalactanprotein AtAGP17 mutant (rat1) that results in a decreased efficiency of agrobacterium transformation. Plant Physiol. 135: 2162-2171.

Gilson P, Gaspar YM, Oxley D, Youl JJ, Bacic A. 2001. NaAGP4 is an arabinogalactan protein whose expression is suppressed by wounding and fungal infection in Nicotiana alata. Protoplasma 215: 128-139.

Gong S-Y, Huang G-Q, Sun X, Li P, Zhao L-L, Zhang D-J, Li X-B. 2012. GhAGP31, a cotton non-classical arabinogalactan protein, is involved in response to cold stress during early seedling development. Plant Biol. Stuttg. Ger. 14: 447-457.

Grishchenko LA, Aleksandrova GP, Medvedeva SA. 2004. Complexation of Arabinogalactan with Copper(II) ions in aqueous solutions. Russ. J. Gen. Chem. 74: 1122-1125.

Grover A. 2012. Plant chitinases: genetic diversity and physiological roles. Crit. Rev. Plant Sci. 31: 57-73.

Haegeman A, Joseph S, Gheysen G. 2011. Analysis of the transcriptome of the root lesion nematode Pratylenchus coffeae generated by 454 sequencing technology. Mol. Biochem. Parasitol. 178: 7-14.

Harrak H, Chamberland H, Plante M, Bellemare G, Lafontaine JG, Tabaeizadeh Z. 1999. A proline-, threonine-, and glycine-rich protein down-regulated by drought is localized in the cell wall of xylem elements. Plant Physiol. 121: 557-564.

Harrison MJ. 1999. Molecular and cellular aspects of the arbuscular mycorrhizal symbiosis. Annu. Rev. Plant Physiol. Plant Mol. Biol. 50: $361-$ 389. 
Hijazi M, Velasquez SM, Jamet E, Estevez JM, Albenne C. 2014. An update on post-translational modifications of hydroxyproline-rich glycoproteins: toward a model highlighting their contribution to plant cell wall architecture. Front. Plant Sci. 5: 395.

Huang G-Q, Xu W-L, Gong S-Y, Li B, Wang X-L, Xu D, Li X-B. 2008. Characterization of 19 novel cotton FLA genes and their expression profiling in fiber development and in response to phytohormones and salt stress. Physiol. Plant. 134: 348-359.

Jensen JK, Sørensen SO, Harholt J, Geshi N, Sakuragi Y, Møller I, Zandleven J, Bernal AJ, Jensen NB, Sørensen C, et al. 2008. Identification of a xylogalacturonan xylosyltransferase involved in pectin biosynthesis in Arabidopsis. Plant Cell 20: 1289-1302.

Johnson KL, Jones BJ, Bacic A, Schultz CJ. 2003. The fasciclin-like arabinogalactan proteins of Arabidopsis. A multigene family of putative cell adhesion molecules. Plant Physiol. 133: 1911-1925.

Jones JDG, Dangl JL. 2006. The plant immune system. Nature 444: 323-329.

Kawaguchi K, Shibuya N, Ishii T. 1996. A novel tetrasaccharide, with a structure similar to the terminal sequence of an arabinogalactan-protein, accumulates in rice anthers in a stage-specific manner. Plant J. Cell Mol. Biol. 9: 777-785.

Kobayashi Y, Motose H, Iwamoto K, Fukuda H. 2011. Expression and genomewide analysis of the xylogen-type gene family. Plant Cell Physiol. 52: 1095-1106.

Komatsu S, Kobayashi Y, Nishizawa K, Nanjo Y, Furukawa K. 2010. Comparative proteomics analysis of differentially expressed proteins in soybean cell wall during flooding stress. Amino Acids 39: 1435-1449.

Komatsu S, Kuji R, Nanjo Y, Hiraga S, Furukawa K. 2012. Comprehensive analysis of endoplasmic reticulum-enriched fraction in root tips of soybean under flooding stress using proteomics techniques. J. Proteomics 77: 531-560.

Lamport DTA, Várnai P. 2013. Periplasmic arabinogalactan glycoproteins act as a calcium capacitor that regulates plant growth and development. New Phytol. 197: 58-64.

Lamport DTA, Kieliszewski MJ, Showalter AM. 2006. Salt stress upregulates periplasmic arabinogalactan proteins: using salt stress to analyse AGP function. New Phytol. 169: 479-492.

Le Gall H, Philippe F, Domon J-M, Gillet F, Pelloux J, Rayon C. 2015. Cell wall metabolism in response to abiotic stress. Plants 4: 112-166.

Lee KJD, Sakata Y, Mau S-L, Pettolino F, Bacic A, Quatrano RS, Knight CD, Knox JP. 2005. Arabinogalactan proteins are required for apical cell extension in the moss physcomitrella patens. Plant Cell 17: 3051-3065.

Li SX, Showalter AM. 1996. Cloning and developmental/stress-regulated expression of a gene encoding a tomato arabinogalactan protein. Plant Mol. Biol. 32: 641-652.

Li Y-Q, Zhang H-Q, Pierson ES, Huang F-Y, Linskens HF, Hepler PK, Cresti M. 1996. Enforced growth-rate fluctuation causes pectin ring formation in the cell wall of Lilium longiflorum pollen tubes. Planta 200:41-49.

Lima RB, dos Santos TB, Vieira LGE, Ferrarese M de LL, Ferrarese-Filho O, Donatti L, Boeger MRT, Petkowicz CL de O. 2013. Heat stress causes alterations in the cell-wall polymers and anatomy of coffee leaves (Coffea arabica L.). Carbohydr. Polym. 93:135-143.

Liu D, Tu L, Li Y, Wang L, Zhu L, Zhang X. 2008. Genes encoding fasciclin-like arabinogalactan proteins are specifically expressed during cotton fiber development. Plant Mol. Biol. Report. 26: 98-113.

Loreti E, van Veen H, Perata P. 2016. Plant responses to flooding stress. Curr. Opin. Plant Biol. 33: 64-71.

Losada JM, Herrero M. 2012. Arabinogalactan-protein secretion is associated with the acquisition of stigmatic receptivity in the apple flower. Ann. Bot. mcs116.

Ma H, Zhao J. 2010. Genome-wide identification, classification, and expression analysis of the arabinogalactan protein gene family in rice (Oryza sativa L.). J. Exp. Bot. 61: 2647-2668.

Ma W, Muthreich N, Liao C, Franz-Wachtel M, Schütz W, Zhang F, Hochholdinger F, Li C. 2010. The mucilage proteome of maize (Zea mays L.) primary roots. J. Proteome Res. 9: 2968-2976.

$\mathrm{Ma} \mathrm{H}$, Zhao H, Liu Z, Zhao J. 2011. The phytocyanin gene family in rice (Oryza sativa L.): genome-wide identification, classification and transcriptional analysis. PLoS ONE 6: e25184.

MacMillan CP, Mansfield SD, Stachurski ZH, Evans R, Southerton SG. 2010. Fasciclin-like arabinogalactan proteins: specialization for stem biomechanics and cell wall architecture in Arabidopsis and Eucalyptus. Plant J. 62: 689-703.

MacMillan CP, Taylor L, Bi Y, Southerton SG, Evans R, Spokevicius A. 2015. The fasciclin-like arabinogalactan protein family of Eucalyptus grandis contains members that impact wood biology and biomechanics. New Phytol. 206: 1314-1327.

Mareri L, Faleri C, Romi M, Mariani C, Cresti M, Cai G. 2016. Heat stress affects the distribution of JIM8-labelled arabinogalactan proteins in pistils of Solanum lycopersicum cv Micro-Tom. Acta Physiol. Plant. 38: 184.

Mashiguchi K, Urakami E, Hasegawa M, Sanmiya K, Matsumoto I, Yamaguchi I, Asami T, Suzuki Y. 2008. Defense-related signaling by interaction of arabinogalactan proteins and beta-glucosyl Yariv reagent inhibits gibberellin signaling in barley aleurone cells. Plant Cell Physiol. 49: 178190.

Mashiguchi K, Asami T, Suzuki Y. 2009. Genome-wide identification, structure and expression studies, and mutant collection of 22 early nodulin-like protein genes in Arabidopsis. Biosci. Biotechnol. Biochem. 73: 2452-2459.

Mau SL, Chen CG, Pu ZY, Moritz RL, Simpson RJ, Bacic A, Clarke AE. 1995. Molecular cloning of cDNAs encoding the protein backbones of arabinogalactan-proteins from the filtrate of suspension-cultured cells of Pyrus communis and Nicotiana alata. Plant J. Cell Mol. Biol. 8: 269-281.

Moore JP, Farrant JM, Driouich A. 2008. A role for pectin-associated arabinans in maintaining the flexibility of the plant cell wall during water deficit stress. Plant Signal. Behav. 3: 102-104.

Motose H, Fukuda H, Sugiyama M. 2001. Involvement of local intercellular communication in the differentiation of zinnia mesophyll cells into tracheary elements. Planta 213: 121-131.

Munnik T, Meijer HJ, Ter Riet B, Hirt H, Frank W, Bartels D, Musgrave A. 2000 Hyperosmotic stress stimulates phospholipase $D$ activity and elevates the levels of phosphatidic acid and diacylglycerol pyrophosphate. Plant J. Cell Mol. Biol. 22: 147-154.

Munns R, Tester M. 2008. Mechanisms of salinity tolerance. Annu. Rev. Plant Biol. 59: 651-681.

Neves GYS, Marchiosi R, Ferrarese MLL, Siqueira-Soares RC, Ferrarese-Filho O. 2010. Root growth inhibition and lignification induced by salt stress in soybean. J. Agron. Crop Sci. 196: 467-473.

Nguema-Ona E, Vicré-Gibouin M, Gotté M, Plancot B, Lerouge P, Bardor M, Driouich A. 2014. Cell wall O-glycoproteins and N-glycoproteins: aspects of biosynthesis and function. Front. Plant Sci. 5: 499.

Nothnagel EA. 1997. Proteoglycans and related components in plant cells. Int. Rev. Cytol. 174: 195-291.

Oliveira AJB de, Cordeiro LMC, Gonçalves RAC, Ceole LF, Ueda-Nakamura T, lacomini M. 2013. Structure and antiviral activity of arabinogalactan with (1 $\rightarrow 6)-\beta$-d-galactan core from Stevia rebaudiana leaves. Carbohydr. Polym. 94: 179-184.

Osakabe Y, Yamaguchi-Shinozaki K, Shinozaki K, Tran L-SP. 2013. Sensing the environment: key roles of membrane-localized kinases in plant perception and response to abiotic stress. J. Exp. Bot. 64: 445-458.

Oxley D, Bacic A. 1999. Structure of the glycosylphosphatidylinositol anchor of an arabinogalactan protein from Pyrus communis suspension-cultured cells. Proc. Natl. Acad. Sci. U. S. A. 96: 14246-14251.

Park MH, Suzuki Y, Chono M, Knox JP, Yamaguchi I. 2003. CSAGP1, a gibberellin-responsive gene from cucumber hypocotyls, encodes a classical arabinogalactan protein and is involved in stem elongation. Plant Physiol.

Parrotta L, Guerriero G, Sergeant K, Cai G, Hausman J-F. 2015. Target or barrier? The cell wall of early- and later-diverging plants vs cadmium toxicity: differences in the response mechanisms. Front. Plant Sci. 6.

Parveen S, Gupta AD, Prasad R. 2007. Arabinogalactan protein from Arachis hypogaea: role as carrier in drug-formulations. Int. J. Pharm. 333: 79-86.

Pennell RI, Roberts K. 1990. Sexual development in the pea is presaged by altered expression of arabinogalactan protein. Nature 344: 547-549.

Pennell RI, Knox JP, Scofield GN, Selvendran RR, Roberts K. 1989. A family of abundant plasma membrane-associated glycoproteins related to the arabinogalactan proteins is unique to flowering plants. J. Cell Biol. 108: 1967-1977.

Pennell RI, Janniche L, Kjellbom P, Scofield GN, Peart JM, Roberts K. 1991. Developmental regulation of a plasma membrane arabinogalactan protein epitope in oilseed rape flowers. Plant Cell 3: 1317-1326. 
Pereira LG, Coimbra S, Oliveira H, Monteiro L, Sottomayor M. 2006. Expression of arabinogalactan protein genes in pollen tubes of Arabidopsis thaliana. Planta 223: 374-380.

Plieth C. 2012. Apoplastic calcium executes a shut-down function on plant peroxidases: a hypothesis. Plant Signal. Behav. 7: 678-681.

Qin L-X, Zhang D-J, Huang G-Q, Li L, Li J, Gong S-Y, Li X-B, Xu W-L. 2013. Cotton GhHyPRP3 encoding a hybrid proline-rich protein is stress inducible and its overexpression in Arabidopsis enhances germination under cold temperature and high salinity stress conditions. Acta Physiol. Plant. 35: 1531-1542.

Rabello AR, Guimarães CM, Rangel PH, da Silva FR, Seixas D, de Souza E, Brasileiro AC, Spehar CR, Ferreira ME, Mehta Â. 2008. Identification of drought-responsive genes in roots of upland rice (Oryza sativa $\mathrm{L}$ ). BMC Genomics 9: 485.

Ruelland E, Cantrel C, Gawer M, Kader J-C, Zachowski A. 2002. Activation of phospholipases $C$ and $D$ is an early response to a cold exposure in Arabidopsis suspension cells. Plant Physiol. 130: 999-1007.

Sánchez-Aguayo I, Rodríguez-Galán JM, García R, Torreblanca J, Pardo JM. 2004. Salt stress enhances xylem development and expression of S-adenosyl-I-methionine synthase in lignifying tissues of tomato plants. Planta 220: 278-285.

Santaniello A, Loreti E, Gonzali S, Novi G, Perata P. 2014. A reassessment of the role of sucrose synthase in the hypoxic sucrose-ethanol transition in Arabidopsis. Plant Cell Environ. 37: 2294-2302.

Sardar HS, Yang J, Showalter AM. 2006. Molecular interactions of arabinogalactan proteins with cortical microtubules and F-actin in bright yellow-2 tobacco cultured cells. Plant Physiol. 142: 1469-1479.

Schultz C, Gilson P, Oxley D, Youl J, Bacic A. 1998. GPI-anchors on arabinogalactan-proteins: implications for signalling in plants. Trends Plant Sci. 3: 426-431.

Schultz CJ, Johnson KL, Currie G, Bacic A. 2000. The classical arabinogalactan protein gene family of Arabidopsis. Plant Cell 12: 1751-1768.

Seifert GJ, Roberts K. 2007. The biology of arabinogalactan proteins. Annu. Rev. Plant Biol. 58: 137-161.

Seki M, Ishida J, Narusaka M, Fujita M, Nanjo T, Umezawa T, Kamiya A Nakajima M, Enju A, Sakurai T, et al. 2002. Monitoring the expression pattern of around 7,000 Arabidopsis genes under ABA treatments using a full-length cDNA microarray. Funct. Integr. Genomics 2: 282-291.

Shabala S, Munns R. 2012. Salinity stress: physiological constraints and adaptive mechanisms. p. 24

Shailasree S, Kini KR, Deepak S, Kumudini BS, Shetty HS. 2004. Accumulation of hydroxyproline-rich glycoproteins in pearl millet seedlings in response to Sclerospora graminicola infection. Plant Sci. 167: 1227-1234.

Shanker AK, Cervantes C, Loza-Tavera H, Avudainayagam S. 2005. Chromium toxicity in plants. Environ. Int. 31: 739-753.

Showalter AM. 2001. Arabinogalactan-proteins: structure, expression and function. Cell. Mol. Life Sci. CMLS 58: 1399-1417.

Showalter AM, Basu D. 2016. Extensin and arabinogalactan-protein biosynthesis: glycosyltransferases, research challenges, and biosensors. Front. Plant Sci. 7.

Showalter AM, Keppler B, Lichtenberg J, Gu D, Welch LR. 2010. A bioinformatics approach to the identification, classification, and analysis of hydroxyproline-rich glycoproteins. Plant Physiol. 153: 485-513.

Speranza A, Ferri P, Battistelli M, Falcieri E, Crinelli R, Scoccianti V. 2007. Both trivalent and hexavalent chromium strongly alter in vitro germination and ultrastructure of kiwifruit pollen. Chemosphere 66: 1165-1174.

Speranza A, Taddei AR, Gambellini G, Ovidi E, Scoccianti V. 2009. The cell wall of kiwifruit pollen tubes is a target for chromium toxicity: alterations to morphology, callose pattern and arabinogalactan protein distribution. Plant Biol. 11: 179-193.

Taddei S, Bernardi R, Salvini M, Pugliesi C, Durante M. 2007. Effect of copper on callus growth and gene expression of in vitro-cultured pith explants of Nicotiana glauca. Plant Biosyst. - IntJ. Deal. Asp. Plant Biol. 141: 194-203.
Tseng I-C, Hong C-Y, Yu S-M, Ho T-HD. 2013. Abscisic acid- and stress-induced highly proline-rich glycoproteins regulate root growth in rice. Plant Physiol. 163: 118-134.

Van Hengel AJ, Roberts K. 2002. Fucosylated arabinogalactan-proteins are required for full root cell elongation in arabidopsis. Plant J. Cell Mol. Biol. 32: 105-113.

Van Hengel AJ, Roberts K. 2003. AtAGP30, an arabinogalactan-protein in the cell walls of the primary root, plays a role in root regeneration and seed germination. Plant J. 36: 256-270.

Van Hengel AJ, Van Kammen A, De Vries SC. 2002. A relationship between seed development, Arabinogalactan-proteins (AGPs) and the AGP mediated promotion of somatic embryogenesis. Physiol. Plant. 114: 637-644.

Vanholme B, Haegeman A, Jacob J, Cannoot B, Gheysen G. 2009. Arabinogalactan endo-1,4- $\beta$-galactosidase: a putative plant cell walldegrading enzyme of plant-parasitic nematodes. Nematology 11: 739747.

Vicré M, Santaella C, Blanchet S, Gateau A, Driouich A. 2005. Root borderlike cells of Arabidopsis. microscopical characterization and role in the interaction with rhizobacteria. Plant Physiol. 138: 998-1008.

Vlad F, Spano T, Vlad D, Bou Daher F, Ouelhadj A, Kalaitzis P. 2007. Arabidopsis prolyl 4-hydroxylases are differentially expressed in response to hypoxia, anoxia and mechanical wounding. Physiol. Plant. 130: 471-483.

Xie F, Williams A, Edwards A, Downie JA. 2012. A plant arabinogalactanlike glycoprotein promotes a novel type of polar surface attachment by rhizobium leguminosarum. Mol. Plant-Microbe Interact. MPMI 25: 250258.

Yan Y, Takáč T, Li X, Chen H, Wang Y, Xu E, Xie L, Su Z, Šamaj J, Xu C. 2015. Variable content and distribution of arabinogalactan proteins in banana (Musa spp.) under low temperature stress. Front. Plant Sci. 6.

Yang S-H, Wang H, Sathyan P, Stasolla C, Loopstra CA. 2005. Real-time RTPCR analysis of loblolly pine (Pinus taeda) arabinogalactan-protein and arabinogalactan-protein-like genes. Physiol. Plant. 124: 91-106.

Yang J, Sardar HS, McGovern KR, Zhang Y, Showalter AM. 2007. A lysine-rich arabinogalactan protein in Arabidopsis is essential for plant growth and development, including cell division and expansion. Plant J. Cell Mol. Biol. 49: 629-640.

Yang J, Li K, Zheng W, Zhang H, Cao X, Lan Y, Yang C, Li C. 2015. Characterization of early transcriptional responses to cadmium in the root and leaf of $\mathrm{Cd}$ resistant Salix matsudana Koidz. BMC Genomics. 16.

Yin X, Nishimura M, Hajika M, Komatsu S. 2016. Quantitative proteomics reveals the flooding-tolerance mechanism in mutant and abscisic acidtreated soybean. J. Proteome Res. 15: 2008-2025.

Yu Q, Wingender R, Schulz M, Baluška F, Goldbach HE. 2001. Short-term boron deprivation induces increased levels of cytoskeletal proteins in Arabidopsis roots. Plant Biol. 3: 335-340.

Yu Q, Baluška F, Jasper F, Menzel D, Goldbach HE. 2003. Short-term boron deprivation enhances levels of cytoskeletal proteins in maize, but not zucchini, root apices. Physiol. Plant. 117: 270-278.

Zagorchev L, Odjakova M. 2011. Hydroxyproline rich proteins in salt adapted embryogenic suspension cultures of Dactylis Glomerata L. Biotechnol. Biotechnol. Equip. 25: 2321-2328.

Zang L, Zheng T, Chu Y, Ding C, Zhang W, Huang Q, Su X. 2015. Genome-wide analysis of the fasciclin-like arabinogalactan protein gene family reveals differential expression patterns, localization, and salt stress response in Populus. Front. Plant Sci. 6.

Zhu JK. 2002. Salt and drought stress signal transduction in plants. Annu Rev Plant Biol. 53: 247-273.

Zhu J-K, Bressan RA, Hasegawa PM. 1993. Loss of arabinogalactan-proteins from the plasma membrane of $\mathrm{NaCl}$-adapted tobacco cells. Planta. 190: 221-226. 